\title{
25 anos do programa de pós-graduação em educação da UFPR
}

\section{5 years of education post-graduation program in UFPR}

\author{
Liane dos Anjos* \\ Leilah Santiago Bufrem** \\ Criar uma nova cultura não significa apenas fazer individualmente \\ descobertas "originais"; significa também, e sobretudo, difundir \\ criticamente verdades já descobertas, "socializá-las" por assim dizer; \\ transformá-las, portanto, em base de ações vitais, em elemento de \\ coordenação e de ordem intelectual e moral.
}

Gramsci

\section{RESUMO}

Analisa os elementos que contribuíram para a concretização do que hoje se constitui o Programa de Pós-Graduação em Educação (PPGE) da Universidade Federal do Paraná (UFPR), a partir da leitura e interpretação de documentos e depoimentos obtidos. Acompanha e analisa suas quatro fases: a inicial, de criação, que vai de 1975 a 1983; a segunda, de 1984 a 1991, a terceira, de 1992 a 1997 e a quarta fase, iniciada em 1998, concluindo que o PPGE se consolidou nesses quatro períodos, cujas características definiram-se pelas iniciativas, limitações e dificuldades que enfrentaram. Considera os resultados como referentes e desafiantes para o conhecimento e a crítica de um processo de consolidação, a partir do qual se deve exercitar a isenção e

* Bibliotecária do Sistema de Bibliotecas, Universidade Federal do Paraná. Mestre em Planejamento e Administração de Sistemas de Informação pela PUC-Campinas. alian@ufpr.br

** Professora Titular do Departamento de Ciência e Gestão da Informação, Universidade Federal do Paraná. Doutora em Comunicação pela USP. bufrem@milenio.com.br 
liberdade na mediação crítico-reflexiva sobre o valor dos atos e dos fatos revelados nessa trajetória.

Palavras-chave: comunicação científica, dissertação, educação, pós-graduação em educação, produção científica, Universidade Federal do Paraná.

\begin{abstract}
It analyzes the elements that contributed to the concretization of what today constitutes the Postgraduate Program in Education (PPGE) of the Federal University of Paraná (UFPR), that is done based on reading and interpretation of the obtained documents and testimonies. It follows and analyzes the four phases of the program: the initial one, or creation, from 1975 to 1983; the second, from 1984 to 1991; the third, from 1992 to 1997; and the fourth phase, since 1998 until today. It comes to the conclusion that PPGE was consolidated throughout these periods, and that its characteristics were defined by decisions, limitations and faced difficulties. It considers the results as referring and challenging to the knowledge and criticism of a consolidation process, from which we should practice exemption and freedom in critic-reflective mediation on the value of the acts and facts revealed throughout this trajectory.

Key-words: scientific communication, thesis, education, post-graduate studies in education, scientific production, Universidade Federal do Paraná.
\end{abstract}

\title{
Introdução
}

Aceitando-se como pressuposto que a sobrevivência da memória coletiva deriva parcialmente de um inventário das condições e das forças que operaram em uma determinada época, o propósito deste artigo é analisar elementos que contribuíram para a concretização do que hoje se constitui o Programa de Pós-Graduação em Educação (PPGE) da Universidade Federal do Paraná (UFPR). Em análise diacrônica, procura-se visualizar os processos evolutivos que contribuíram e vêem contribuindo para revitalizar compromissos institucionais e compreender o presente. 
Recuperar a trajetória do programa, a partir da leitura e interpretação dos documentos e depoimentos obtidos, importou acompanhar suas quatro grandes fases: a inicial, de criação, que vai de 1975 a 1983; a segunda, de 1984 a 1991, a terceira, de 1992 a 1997 e a quarta fase, que se inicia em 1998.

\section{Do projeto à consolidação}

Como conseqüência da reforma universitária iniciada em 1967, ocorreu em 1971 o desmembramento da Faculdade de Filosofia, Ciências e Letras, da UFPR, em Faculdade de Educação, Faculdade de Ciências Humanas, Letras e Artes e Faculdade de Biblioteconomia e Comunicação Social. Mas foi com a setorialização da universidade (Decreto $n^{\circ} 72.717$, de 29 de agosto de 1973) ${ }^{1}$ que a Faculdade de Educação passou a denominar-se Setor de educação (SE), constituindo-se dos Departamentos de Teoria e Fundamentos de Educação, Métodos e Técnicas de Educação, Planejamento e Administração Escolar e Biblioteconomia. Em 1987, o Departamento de Biblioteconomia foi transferido do Setor de educação para o Setor de Ciências Humanas, Letras e Artes. A partir de então, outras mudanças ocorreram e atualmente o Setor de educação é constituído pelos departamentos de Planejamento e Administração Escolar (Deplae), de Teoria e Prática de Ensino (Detpen ) e de Teoria e Fundamentos da Educação (DTFE).

Em 22 de agosto de 1974, o Conselho Universitário da UFPR autoriza a criação e instalação, no Setor de educação, do Curso de Pós-Graduação em Educação, em nível de Mestrado, de acordo com o plano curricular apresentado (Resolução 07/74). ${ }^{2}$ Segundo a professora. Zélia M. PAVÃO (2001), ${ }^{3}$ por sugestão da Capaes e atendendo a critérios da política central

$1 \quad$ Decreto no 72.717, de 29 de agosto de 1973.

2 Em 22 de agosto de 1974, o Conselho Universitário da UFPR autoriza a criação e instalação, no Setor de Educação, do Curso de Pós-Graduação em Educação, em nível de Mestrado, de acordo com o plano curricular apresentado (Resolução 07/74).

3 PAVÃO, Z. M. Entrevista concedida pela Diretora do PPGE da UFPR: 1982-91. Curitiba, 14 mar. 2001. 
de distribuição dos cursos por regiões, escolheu-se a área de concentração de uma relação apresentada pelo órgão, com o objetivo de obter o apoio financeiro necessário. Para o estabelecimento de prioridades de áreas de concentração, cada programa deveria considerar a manutenção de um corpo organizado de conhecimentos, levando em conta aspectos relevantes do desenvolvimento regional ou nacional.

...meu olho bateu direto em Currículo, imaginei ser uma área que deveria ser trabalhada por, pelo menos, um professor de cada departamento, para que o currículo deixasse de ser entendido como aquela listagem de disciplinas e passasse a ter uma concepção mais moderna, apoiada na interdisciplinaridade, na comunicação, na pesquisa e na epistemologia. É no relacionamento do conteúdo das disciplinas com o contexto social que está o significado e a utilidade do currículo...

As palavras da ex-diretora do SE oferecem um panorama sucinto de uma visão crítica, então presente nas discussões sobre o currículo, sobre a necessidade de interrogar as complexas realidades escolares em que se desenvolve, abrangendo a compreensão necessária das dimensões presentes na construção dos seus componentes.

Instalado em 1975 e reestruturado para nova área de concentração em 1976, o mestrado inseriu-se naquela que foi considerada a década da pós-graduação, quando a organização e expansão do sistema foram incentivadas por uma política de investimentos federais e estaduais.

Inicialmente, a criação do programa, se por um lado, ligava-se à demanda de formação e aperfeiçoamento de professores superiores, principalmente no campo da pedagogia, responsável pelo preparo do magistério que atuava nas escolas de primeiro e segundo graus, por outro, visava prioritariamente à formação de técnicos de alto nível, reclamados pelos setores de planejamento e administração do ensino nos órgãos federais, estaduais e municipais. Todavia, o projeto original, direcionado para a área do Planejamento Educacional e Metodologia do Ensino, realinhou-se para um objeto mais específico da área, o Currículo. Essa alteração na área de concentração obedeceu a razões de ordem nacional quanto à execução da política educacional e, de ordem estadual, para suprir a demanda de especialistas em currículo. 
Para caber na nova roupa, o Programa contratou numerosos especialistas, quer nacionais quer estrangeiros, os quais aqui deixaram importante contribuição. Tais especialistas foram em parte absorvidos pelo quadro permanente da Universidade. Os restantes, dispensados ao final de suas contratações, deixaram, entretanto discípulos e sucessores (BARTHELMESS, 2001). ${ }^{4}$

Como conseqüência, integraram-se ao quadro do PPGE professores visitantes, especializados na nova área definida. A área de currículo passa a ser influenciada pelas matrizes conceituais norte-americanas, em razão da formação dos especialistas recém-incorporados, tanto brasileiros que haviam feito o doutorado nos Estados Unidos, quanto quatro doutores norteamericanos. O corpo docente, em 1977, era composto por 25 professores, sendo 5 estrangeiros.

Para compor o corpo discente, exigia-se do candidato o regime de tempo integral ao PPGE, ou seja, de 40 horas semanais para terminar o Curso em uma duração mínima de 18 meses, excluída a dissertação. A duração máxima era de 48 meses (4 anos), incluída a dissertação. Era conferido o grau de Mestre em Educação ao aluno que, aprovado nas disciplinas e atividades do programa, com média global não inferior a 8 , equivalente ao conceito "B" (09-10 = A; 08-09 = B), tivesse sua dissertação aprovada em argüição pública, diante da banca examinadora, composta de três membros e tivesse cumprido todas as formalidades regimentais concernentes às disciplinas, documentos e dissertação.

Segundo relatórios da coordenação do PPGE, no início do programa, o número de candidatos era menor que o número de vagas (20). Nos anos de 1979, 1980 e 1981, foi se intensificando a demanda, conforme demonstram os números de candidatos admitidos no curso introdutório, constituído regimentalmente como o principal instrumento de seleção (38 em 1979, 44 em 1980 e 65 em 1981). Nos primeiros anos, predominavam candidatos docentes atuantes nos mais diversos setores da UFPR, presumivelmente interessados em aprimorar seu desempenho didático, aliando os conheci-

4 BARTHELMESS, V. A. C. Entrevista concedida pelo Coordenador do PPGE. da UFPR: 1978-79 e 1980-81. Curitiba, 20 mar. 2001. 
mentos de conteúdo específico das disciplinas que lecionavam nos setores de origem com a formação pedagógica que pretendiam adquirir. A ampliação desse contingente foi motivada, por um lado, pelas prescrições que exigiam o grau de mestre para os processos de ascensão e, mais tarde, para a permanência dos professores nos quadros das universidades, e por outro, pela inexistência de cursos de pós-graduação em outras áreas.

A partir dos anos 80 , percebe-se a predominância de não-docentes (em geral, pessoal de nível superior da administração pública ligado às tarefas de planejamento e supervisão da rede escolar estadual e municipal), bem como de professores de outras instituições de Ensino Superior, inclusive do Norte e Nordeste do país. Candidatos de outras áreas também foram atraídos para o programa, malgrado a falta de conhecimentos elementares da área de educação, tais como conceitos, terminologia, classificações, relações, metodologia da pesquisa científica em educação, entre outros. Além de poucos alunos serem dispensados de suas atividades profissionais, uma vez que o curso passava a ser acréscimo de trabalho, alunos provenientes de outras instituições e de outros Estados, embora integralmente devotados ao estudo, viam-se obrigados a maximizar o tempo de trabalho acadêmico para retornar às suas instituições.

Deve-se observar que com a escolha da área de concentração currículo não se pretendia formar o tecnólogo de currículo, mas o teórico nesse campo de estudo, intento, no entanto, frustrado pela rígida linha de disciplinas obrigatórias, o que tornou demasiado convergente o perfil profissional do egresso do curso. O currículo inicial desfigurou-se pela inclusão, na área de concentração, de seminários direcionados para o aspecto formal da elaboração da dissertação. Criados para sanar as dificuldades dos alunos nesse tipo de construção intelectual, acabaram virando uma camisa-deforça quando passaram a ser obrigatórios e vinculados à área de concentração, a qual deveria apoiar-se em apenas duas de suas disciplinas, Tomada de decisões em currículo e Desenvolvimento de currículo na escola brasileira.

Em razão dessas observações, em 1982, depois de quase uma década de vivência especulativa sobre a questão curricular, objetivando seu aprimoramento, e sob pressão de uma demanda provocada por uma clientela diferenciada, o PPGE deu início a uma detalhada auto-avaliação, da qual derivou não apenas uma reformulação curricular, como também uma proposta para instalação de outra área de concentração, conforme as recomendações sugeridas ao PPGE e constantes da Ficha de Análise e Avaliação 
de cursos de Pós-Graduação - MEC-Capes, referente ao período do $2 .^{\circ}$ semestre de $1980-1 .^{\circ}$ semestre de 1981.

Com a primeira revisão do programa, que até então tinha apenas uma área de concentração (currículo), com 154 dissertações defendidas, aprovou-se, em 1983, a segunda área de concentração, Recursos Humanos e Educação Permanente, mais identificada com a orientação européia de educação continuada, difundida pela Unesco. A proposta específica para o funcionamento dessa área foi apresentada e incluída no mesmo expediente de recredenciamento da área de concentração em currículo. Foi autorizado pelo Conselho Federal de Educação (Parecer n. 640, de 14/9/84) o funcionamento da nova área de concentração de Recursos Humanos e Educação Permanente, em caráter experimental, para que se pudesse proceder ao acompanhamento e avaliação da Capes, assim como aprovado seu credenciamento, até 1989. Como resultado, o PPGE mereceu conceito B+ (concernente ao período 1983/84), ascendendo de um conceito C, atribuído, em 1981 e B, em 1982, passando a compor o rol de cursos recomendados. O conceito B+ repetiu-se nas avaliações referentes aos anos 1985/ 86 e 1987/88/89. Nos anos 90, o programa obteve sucessivos conceitos C (1990/91; 1992/93; 1994/95) e nota 3 em 1996/97. Em 1998, inaugurou-se a periodicidade trienal para as avaliações, e as visitas in loco passaram a ser feitas nos anos intercalares do processo avaliativo, com base nas sugestões dos comitês de avaliação (CAPES, 1995; CAPES, 1998; CAPES, 1999). Na última avaliação, em 2001, o programa recebeu nota 5, segundo o novo sistema de atribuição da Capes.

A reformulação curricular de 1984 ensejou a concretização de uma nova concepção estrutural, redefinindo disciplinas e reorientando conteúdos, com renovação do quadro docente, remanejamento de créditos, acréscimo de vagas, alteração do processo seletivo e redução de carga horária.

Percebe-se que a incerteza e a carência de recursos, somadas à inexistência de mecanismos de entrosamento institucional, haviam provocado descontinuidades e dicotomias, não só por causa da estrutura curricular da área de concentração em currículo, anacrônica em razão do excessivo número de créditos obrigatórios, mas também e principalmente pela ausência de linhas e de núcleos temáticos de pesquisa. A soma desses fatores conduziu a produção científica do programa a uma enorme pulverização e à falta de integração entre produção docente e discente. Nessa conjuntura, a posição do PPGE, a partir de 1984, traduziu-se no acolhimento aos aspirantes ao mestrado, oriundos de outras áreas do conhecimento. Essa aber- 
tura, característica de um programa pluralista e flexível, impôs-se de maneira gradativa e, aparentemente, sem prejuízo de canalização de prioridades, como a formação de professores do Ensino Superior, por exemplo.

A reformulação curricular, conseqüentemente, despertou uma atitude epistemológica mais condizente com a vida institucional e o contexto científico brasileiros, cujas tendências demonstravam maior liberdade em relação aos ditames positivistas. O processo de reflexão iniciado por ocasião do recredenciamento estendeu-se até 1990, sempre sob novas perspectivas e prospectivas de ação. Nesse processo, ressalta-se um marco, que se constituiu na publicação da obra Pensando Currículo, em 1988, na qual são expostos à comunidade científica de educadores a produção de parte do corpo docente e alguns trabalhos do corpo discente sobre o tema currículo.

Em 1986 e 1988, não houve oferta de vagas para ingresso na área de currículo, a fim de favorecer a expansão da área de Recursos Humanos e Educação Permanente, que se instalara em 1984. A evolução da demanda por si só justificaria a oferta do PPGE em suas duas áreas de concentração. Todavia, cabe aprofundar a justificativa em face do contexto da época.

O Paraná contava com, aproximadamente, 50 instituições de Ensino Superior, entre elas, cinco universidades, além da Universidade Federal do Paraná. As instituições estavam distribuídas pelo interior do Estado, formando uma rede em expansão, de caráter diversificado. A política estadual do Ensino Superior estava voltada à qualificação da rede existente como preâmbulo desta expansão. Além disso, os sistemas de ensino de primeiro e segundo graus na esfera estadual, e de primeiro grau na esfera municipal de Curitiba, estavam incrementando pesquisas e mudanças curriculares e metodológicas de impacto. Por outro lado, o porte e a complexidade das organizações públicas e empresariais privadas, no Estado, abriam espaço ao desenvolvimento de seus quadros de modo saliente, desafiando a projeção de estratégias e mecanismos de educação permanente (CERVI, 2001). ${ }^{5}$

5 CERVI, R. de M. Entrevista concedida pela Coordenadora do PPGE da UFPR: 1988-89 e 1990-91. Curitiba, 05 abr. 2001. 
A partir do surgimento da ênfase teórico-explicativa, que redimensionou o Currículo como área de conhecimento e contribuiu para a sistematização do campo e a definição e fortalecimento das linhas de pesquisa que viriam a ser implantadas em 1992, o enfoque de estudos normativo-práticos foi revitalizado.

Essa possibilidade de diferenciação e de integração, tanto no campo epistemológico-teórico, como no campo técnico e ideológico, almejava constituir a riqueza, a força, a necessidade e a oportunidade do PPGE. Como ilustração, no ano de 1990, inscreveram-se no programa 102 candidatos, dos quais 8 eram docentes da UFPR, 28 eram docentes de outras IES e 66 eram não-docentes.

Entretanto, no segundo período letivo de 1991, as anunciadas políticas de revisão constitucional do governo Collor de Mello, particularmente as referentes à aposentadoria, esvaziaram os programas, o que provocou transformações no perfil da pós-graduação. No PPGE, esse movimento causou a perda de 14 professores doutores do corpo permanente, todos aposentados por tempo de serviço, ao mesmo tempo que possibilitou uma mudança radical em termos de concepção do programa. Tal situação, por um lado, caótica, constituiu-se numa ameaça à própria sobrevivência do programa, interferindo nas tradicionais linhas de pesquisa por ele mantidas e inviabilizando a oferta de novas vagas. Por outro lado, contudo, criou-se a oportunidade de reestruturação, uma vez que dos quatro professores orientadores remanescentes em 1991, três doutores do programa foram responsáveis por uma produção científica, articulada à formação de quadros, em torno de temáticas específicas da área, tais como, educação $e$ trabalho, cognição e aprendizagem e currículo e conhecimento. Na época, o PPGE contava com 103 mestrandos, com o curso por concluir (45 deles com o tempo de conclusão esgotado).

Diante desse fato insólito, duas opções apresentavam-se ao programa, ou ele encerraria suas atividades, ou buscaria uma forma alternativa de sobrevivência, sem abrir mão de sua qualidade acadêmica. O colegiado optou pela segunda alternativa. Assim, emergindo de uma proposta discutida com toda a comunidade do setor de educação, empreendeu-se uma modificação radical na estrutura curricular e na filosofia do programa, enfatizando-se as linhas de pesquisa e não as disciplinas.

Era necessário, para sustentar as novas pretensões do curso, estabelecer um novo aparato jurídico, concretizado pelo Regimento, que entrou em vigor em 24 de abril de 1992 (Resolução 35/92 - CEP), ainda não o 
desejado mas, certamente, mais ajustado às pretensões, necessidades e possibilidades da época. A reformulação, levada a efeito em 1992, deu início a um novo percurso que começava a impulsionar a pesquisa. Porém, ainda não era possível perceber uma maior articulação entre as áreas de concentração, linhas de pesquisa e produção discente, em face das condições existentes e da própria história do PPGE.

Instituíram-se como linhas de pesquisa, em 1992, nas áreas de Currículo e Recursos Humanos e Educação Permanente: Cognição, Aprendizagem e Interação Social; Educação e Trabalho e Currículo e Conhecimento (UNIVERSIDADE, 1995).

Em 1993, instituiu-se uma nova linha - Arte-Educação. Tomaram-se como referência, para a instituição das linhas, a produção na área e as demandas para os temas de que tratavam.

Ainda em 1992, o PPGE recompôs seu corpo docente, passando a contar com 11 professores doutores, ampliando, no ano seguinte para 12 e, em 1994, para 13 professores doutores do quadro permanente. Em 1995, o quadro docente de 12 doutores e o fluxo de alunos começaram a estabilizar-se.

O PPGE passou a ser considerado um programa consolidado e, por isso mesmo, com condições de adquirir maior presença na área da educação, de um ponto de vista nacional. A situação do corpo docente permanente era muito boa, tanto em termos quantitativos, como de qualificação e de regime de trabalho. A dependência de professores participantes era mínima, e a titulação do corpo docente realizada em lugares bem diversificados (Estados Unidos, França, Espanha, Bélgica, Alemanha, Itália, Vaticano e Brasil). O ensino e a orientação eram assumidos integralmente pelo corpo docente permanente, com boa relação orientando/orientador. O PPGE estava num momento ascendente, entretanto, ainda deveria fazer esforços para titular os professores mestres, listados no programa, alguns dos quais com muitos orientandos.

O número de dissertações defendidas era razoável e ascendente, mas os temas, por serem muito diversificados e, em geral, heterogêneos, não se articulavam satisfatoriamente com os núcleos temáticos do programa.

A demanda para o programa continuava numerosa e diversificada. Notava-se uma tendência de aumento na proporção dos docentes do Ensino Superior que atuavam nas mais diversas áreas, comparada à fração daqueles que atuavam na área da educação. Esse fato se deve, possivel- 
mente, à ampliação da relevância social das questões educacionais por meio de sua discussão pública e à legislação que tende a reforçar essa tendência.

Em 1995, o PPGE voltou a ter um corpo docente permanente estável. Restabeleceu-se o equilíbrio entre docentes/discentes, reduziu-se o tempo médio de conclusão de curso e ampliou-se a participação de discentes/ docentes em seminários e encontros nacionais, assim como a participação de professores externos na composição das bancas examinadoras de dissertação. A estrutura do programa continuava a manter duas áreas de concentração Currículo e Recursos Humanos e Educação Permanente que, a partir de 1995, passaram a ter suas respectivas linhas de pesquisa. Á área de concentração Currículo correspondiam, como linhas de pesquisa, Cognição, Aprendizagem e Interação Social; Currículo e Conhecimento e Arte-Educação, enquanto à área de concentração Recursos Humanos e Educação Permanente correspondia a linha de pesquisa Educação e Trabalho.

Ao ingressar no programa, o mestrando optava por uma área e por uma das linhas de pesquisa própria da área, passando a desenvolver seus estudos sobre a área de uma perspectiva particular, a da linha de pesquisa. Com o programa de acompanhamento, sugerido pela Capes, começou a decrescer o tempo para conclusão do curso.

Superadas as dificuldades do início dos anos 90, à medida que os novos quadros formados foram se incorporando ao programa, foi possível aprofundar, em processo de auto-avaliação, a discussão sobre sua concepção curricular e sua vocação, do que resultou uma nova proposta em 1998.

Desenvolveram-se diagnóstico e mapeamento da produção docente e discente do curso, desde o início dos anos 90, com a finalidade de identificar suas características anteriores e atuais, com vistas a alterações da estrutura curricular, à manutenção, ou não, das linhas de pesquisa existentes e à criação de novas linhas a partir de grupos emergentes de pesquisa.

Em 19 de setembro de 1997 aprovou-se, ad-referendum do Conselho Setorial do Setor de educação, a reformulação do curso de mestrado em Educação. A reformulação proposta visava atender a sugestões da equipe de avaliação da Capes.

Iniciou-se, a partir de outubro de 1997, um processo de discussão sobre a reorganização do programa nas plenárias departamentais, formando-se comissão específica para esse fim, em cada um dos três departamentos do SE. Solicitou-se, a essas comissões, que a partir da análise das dificuldades apontadas nos quesitos presentes na avaliação do programa no 
biênio 1994-1995, tais como, corpo docente, projetos de pesquisa, produção intelectual, e outros, inventariassem a situação do Departamento em cada um desses quesitos, no ano de 1998. Solicitou-se ainda, em face da grande quantidade de professores em processo de doutoramento, uma análise das futuras ofertas para o PPGE. Com base nesses relatórios, que apontaram caminhos e que foram apresentados e discutidos, tanto em plenárias departamentais quanto em reuniões docentes do programa, tomou-se a decisão de estruturar o PPGE somente em torno de linhas de pesquisa.

A reformulação levada a efeito em 1998, academicamente mais consistente, tinha a preocupação de impulsionar decisivamente a pesquisa.

Assim, como destaque nessa reformulação, extinguiram-se as áreas de concentração, reorganizaram-se as linhas de pesquisa, retirando-se a de Arte-Educação e criando-se a linha História e Historiografia da Educação, considerada necessária em razão do aumento da produção docente e discente nessa área.

Observa-se que a reorganização das linhas anteriores de pesquisa Cognição e Aprendizagem para Cognição e Aprendizagem Escolar e Currículo e Conhecimento para Currículo, Conhecimento e Saberes nas Práticas Escolares - visou explicitar seu objeto de estudo na perspectiva da Educação Escolar (ensino formal), e a linha de Educação e Trabalho para Organização e Gestão dos Processos de Formação Humana buscou ampliar seu espectro de investigação, explicitando uma característica que a acompanha desde sua criação, relativa à organização e gestão de propostas e políticas educacionais direcionadas para a Educação Escolar, para a Educação NãoEscolar e para a Educação Permanente.

Novas tendências definiram-se a partir dos doutorados realizados pelos docentes nas grandes universidades do país (PUC-SP, USP e Unicamp), e possibilitaram uma ampliação significativa da esfera de investigação. Toda essa trajetória do setor de educação e dos departamentos no esforço de reconstrução do PPGE, tendo em vista o contexto de complexidade e de dinâmica intensa que definem a organização do campo acadêmico, teve como pressupostos básicos: a relação orgânica com as demandas educacionais da realidade na qual o programa está inserido e a ênfase na natureza interdisciplinar dos recortes dados aos objetos nas linhas de pesquisa.

No ano de 1998, a Resolução 79/98 - Cepe fixou o currículo do curso de Pós-Graduação em Educação, identificando disciplinas básicas que davam organicidade e identidade ao curso. 
Foram reformuladas substantivamente suas linhas de pesquisa e passou-se a investir seriamente na consolidação de um projeto de pós-graduação de qualidade acadêmica e investigativa, para o que muito contribuiu o fato de que todos os docentes do programa eram doutores.

A característica multidisciplinar cada vez mais se consolida, a partir da natureza dos objetos de investigação, sem que se perca a especificidade e a natureza dos processos educativos. Nesse sentido, destaca-se o credenciamento de novos docentes doutores, cuja produção e pesquisa apresentaram grande organicidade com suas respectivas linhas.

Além disso, para superar a questão da excessiva abrangência de algumas linhas ativas, antes da reestruturação, a comissão de avaliação recomendou articulações e delimitações com o intuito de evitar dispersão e que campos do conhecimento pedagógico, hoje bastante especializados, como por exemplo, Educação Matemática, acabem restringindo-se a uma linha de pesquisa em um todo não definido.

O ano de 1998 marcou, assim, uma transição na organização das atividades de pesquisa, com a desativação de quatro linhas e apresentação de outras quatro, que englobaram as linhas desativadas, delimitando-se mais claramente os objetos de investigação, como elementos centrais no processo de aglutinação dos projetos de pesquisa.

A avaliação das atividades de pesquisa registrou, ao longo dos anos 90, um aumento crescente do corpo discente de graduação e de pós-graduação, nos projetos de pesquisa.

Em 1999/2000, a dimensão do corpo discente em relação à dimensão do Núcleo de Referência Docente número 6 ou NRD6 = conforme classificação da Capes $^{6}$ foi de 87 alunos para 15 NRD6, o que corresponde a 5,8 alunos por docente, atestando que a situação vem melhorando sensivelmente sob o aspecto relação professor/aluno. Além disso, o número de desistências e/ou abandonos oscilou no período e, no ano de 1999, todas as saídas foram por titulação.

Em relação à produção discente, também aumentou a quantidade de discentes-autores e, do ponto de vista qualitativo, pode-se afirmar que o vínculo entre áreas de concentração, linhas de pesquisa, projetos de pes-

6 Núcleo de Referência Docente número 6 ou NRD6 = conforme classificação da CAPES. 
quisa e dissertações apresentadas, que vinha demonstrando problemas, a partir de 1998 foi considerado bom. Isso porque constata-se maior vinculação entre os títulos, as ementas das linhas e dos projetos e os resumos das dissertações.

Quanto à produção intelectual docente, sabe-se que, em 1999/2000, o vínculo da produção intelectual docente com a proposta global do PPGE (linhas de pesquisa e projetos de pesquisa) está claro, indicando que o programa considerou as recomendações das avaliações anteriores no sentido de explicitar melhor tais vínculos.

Como decorrência desse processo, defendeu-se um expressivo número de dissertações em 1999 (27) e, em 2000, (33).

No final da década de 90, para atender à exigência da Capes, o PPGE passa a discutir a necessidade de acompanhar o trabalho dos pós-graduados, para avaliar seu impacto no contexto do desenvolvimento do país, o que, para SPAGNOLO; GÜNTHER (1986, p. 1658), “não é tarefa fácil, pois esbarra em problemas conceituais e metodológicos complexos." Entretanto, uma das virtudes desse processo de acompanhamento é a discussão e circulação de novas idéias, tanto em salas de aula quanto por meio de publicações científicas.

Uma maneira de avaliar a produtividade dos egressos é, portanto, a análise de suas publicações, livros, capítulos de livros, artigos de periódicos, apresentações em congressos e seminários, bem como o acompanhamento de suas orientações de trabalhos acadêmicos e de dissertações de mestrado (VIEIRA, 2001). ${ }^{7}$

A análise da produção discente das diferentes linhas demonstra, além da busca de consolidação da coerência explicitada na coesão/vinculação entre linhas de pesquisa e produção discente (dissertações), a maturação de um processo de articulação e dinamização dos grupos/núcleos de pesquisa do PPGE.

Novos ajustes fizeram-se necessários dois anos depois da reestruturação de 1998, malgrado os avanços relativos à integração e ao delineamento de seus objetivos. Isso porque, segundo a Proposta para Doutorado, apresentada no ano de 2000, o programa ainda não refletia a realidade da pesquisa no setor de educação, em razão das limitações identificadas e do reajuste decorrente da participação de novos doutores. A nova proposta deveria

7 VIEIRA, C. A. Entrevista concedida pelo Coordenador do PPGE da UFPR: 2001. Curitiba, 13 jun. 2001. 
considerar a realidade das linhas de pesquisa do mestrado, e procurar criar um doutorado para atender a uma demanda que se ampliava regionalmente, ou seja "a criação de um doutorado em educação, público, a partir de uma tradição consolidada de pesquisa e de um grupo experiente de pesquisadores" (UNIVERSIDADE, 2000).

A proposta visou à definição e articulação das linhas de pesquisa, a partir de seus objetos, com base nos projetos de investigação em curso e à maior coerência interna das linhas de pesquisa, articulando projetos de pesquisa e produção docente e discente.

O mesmo documento salienta a vocação interdisciplinar do programa, evidenciada no seu percurso histórico de construção e consolidação, que exigiu a "convivência com rupturas e descontinuidades" na consolidação de linhas de pesquisa, com vistas a construir respostas às demandas da realidade brasileira contemporânea. Destacam-se, neste percurso, o enfrentamento concreto "das precariedades de uma realidade educacional resultante de uma sociedade crescentemente excludente" e a perspectiva da "construção da cidadania real" característica do programa. Ou seja, a produção teórica articulada a um radical compromisso com a intervenção, tendo em vista a construção de relações sociais e econômicas nas quais sejam garantidos não só o direito à educação de qualidade, mas também todos os direitos. Essa concepção, se por um lado reveste o programa de maior complexidade, por outro, define seu vigor e sua fecundidade (UNIVERSIDADE, 2000).

A compreensão de que a pedagogia é prática cultural intencional e sistematizada de formação humana implica que os processos pedagógicos, fundamentados nesse pressuposto, incorporem e superem as práticas anteriores em suas formas de trabalho, em seus conteúdos, métodos, espaços e atores (UNIVERSIDADE, 2000), do que se depreende a justificativa para a criação do doutorado.

Os 25 anos de história do mestrado compõem uma trajetória consolidada graças aos esforços que se somaram no período e atestaram a existência das condições necessárias para a implantação do doutorado. Dessa maneira, a comissão da avaliação da Capes, depois de considerar as condições favoráveis do programa, recomendou, em 13 de junho de 2002, a implantação do doutorado.

Em 2000, transcorridos dois anos da última reformulação, o PPGE procedeu a uma nova avaliação, o que resultou em uma proposta voltada à realidade das áreas temáticas e linhas de pesquisa. A Resolução 02/01 - 
Cepe, de 9 de fevereiro de 2001, fixa o currículo stricto sensu do PPGE, que passa a ter uma nova configuração, oferecendo três áreas temáticas, com função de aproximar e articular os objetos das linhas de pesquisa.

- Área temática: escola, cultura e processos de ensino-aprendizagem.

Linhas: cognição e aprendizagem escolar;

Educação matemática e processos de aprendizagem;

Saberes, cultura e práticas escolares;

- Área temática: história e historiografia da educação.

Linha: instituições, intelectuais e cultura escolar;

- Área temática: educação e trabalho.

Linhas: economia política da educação;

Políticas e gestão da Educação;

Educação e profissionalização: políticas e processos;

Educação, saúde e trabalho (UNIVERSIDADE, 2000).

E importante destacar que a reformulação que criou essa nova proposta é resultado de um profundo processo de construção e de reconstrução ocorrido no interior das linhas de pesquisa e do programa, por meio de longos períodos de estudos e discussões e, também, como parte da política setorial, que estimulou o desenvolvimento e a consolidação da pesquisa e da formação inicial e continuada de pesquisadores, mediante a implementação do Plano Setorial de Qualificação, produzindo acúmulo de experiência e resultados concretos de pesquisa.

Além dos avanços na qualificação do corpo docente, outros aspectos a serem considerados como parte da institucionalização da pesquisa no setor são a consolidação do Centro de Pesquisas em Educação - Ceped, do Centro de Assessoramento Pedagógico - Ceape, a criação e institucionalização dos Núcleos Temáticos e, com a preocupação de divulgar a produção científica nacional e internacional significativa da área, a reformulação do projeto editorial da Educar em Revista, periódico do setor. 


\section{Conclusão}

Com a recuperação da trajetória do programa, a partir da leitura e interpretação dos documentos e depoimentos obtidos, conclui-se que o PPGE consolidou-se atravessando quatro períodos, cada qual encerrando momentos com características próprias.

O inicial, de criação, que vai de 1975 a 1983, é caracterizado, principalmente, pela presença de professores estrangeiros - norte-americanos em sua maioria - e de brasileiros qualificados nos Estados Unidos. Outra característica marcante dessa fase é o currículo excessivamente fechado do Programa.

O segundo período, de 1984 a 1991, caracteriza-se pela formação de um corpo docente nacional, com a preocupação essencial de atender à demanda de formação e aperfeiçoamento de docentes de Ensino Superior, responsáveis pela formação de professores para atuar nas escolas de primeiro e segundo graus. Introduziu-se, nessa fase, a auto-avaliação formal e intensiva do curso, cujos ganhos acadêmicos foram reconhecidos, destacando-se, dentre eles, a atribuição do conceito $\mathrm{B}+$ pela Capes, quando o programa passa a ser tido como consolidado e, por isso mesmo, em condições de despontar em nível nacional. Foi quando ocorreu a primeira reformulação da estrutura curricular, o que resultou em maior flexibilização do currículo e na introdução de nova área de concentração de cunho social, no escopo dos estudos da educação. Entretanto, nesse período o programa passa por um momento de crise, provocado pelas aposentadorias, o que ameaçou a sua sobrevivência.

No terceiro período, de 1992 a 1997, estrutura-se um novo aparato jurídico - o Regimento - acompanhado de uma segunda reformulação da estrutura curricular, a criação de quatro linhas de pesquisa e a segunda auto-avaliação do programa. Inicia-se uma lenta recuperação do reduzido número de doutores, o que acontece sem que uma política nacional de qualificação de quadros houvesse se consolidado. Essa defasagem só seria superada, a partir de 1995.

O momento inicial da quarta fase (iniciada em 1998) é caracterizado por uma nova reformulação curricular, desta vez com a preocupação de impulsionar a pesquisa. Para tanto, extinguem-se as áreas de concentração 
(e também da linha de pesquisa Arte-Educação), reorganizam-se as linhas de pesquisa consolidadas e abrem-se novas perspectivas investigativas.

O momento atual dessa quarta fase é caracterizado pela implantação do doutorado, quando o programa passa a abranger os cursos de especialização, mestrado e doutorado. A criação do doutorado representa um marco na história da educação pública no Paraná.

O programa de mestrado, no período de 1977 a 2000, formou 370 mestres, dos quais 252 na área de concentração de currículo, 90 na área de concentração de recursos humanos e educação permanente e os outros 28 , nas demais linhas de pesquisa.

A análise dos dados levantados permite concluir que essa produção seguiu uma trajetória consoante às condições do contexto em que se desenvolveu.

Trabalhar com práticas educativas e refletir sobre elas significa trabalhar com as rupturas e as (des)continuidades, como se pode perceber analisando a produção acadêmica do PPGE/UFPR que, se não é apenas um reflexo dos ajustes determinados pelas contingências históricas, antes mostra a busca intencional da construção de uma cidadania real.

Isso porque um programa de pós-graduação deve estar sempre em condições de exercer a crítica e nomear as diferenças que o integram. Assim, considera-se que muito ainda está para ser feito, pois estudos como este são parte integrante do pensar universitário, não podendo ser conclusivos. Pelo contrário, tornam-se referentes e desafiantes para o conhecimento e a crítica da sociedade em que se vive e que se procura transformar, o que possibilita exercitar a isenção e liberdade na mediação críticoreflexiva sobre o valor dos atos e dos fatos revelados nessa trajetória.

CASTRO, C. de M. Na contramão da história. Veja, São Paulo, v. 34, n. 


\section{REFERÊNCIAS}

ANJOS, L. Programa de Pós-graduação em Educação da Universidade Federal do Paraná: tendências temáticas das dissertações (1977-2000). Campinas, 2001. 309 f. Dissertação (Mestrado em Biblioteconomia e Ciência da Informação) - Departamento de Pós-Graduação em Biblioteconomia, Pontifícia Universidade Católica de Campinas.

BRASIL. Ministério da Educação e Cultura. IV Plano Nacional de Pósgraduação: versão preliminar. Brasília, 1999. 8 p. Digitado.

CAPES. Programa de Pós-Graduação em Educação: linhas operacionais. Porto Alegre: UFRGS/Capes, 1976. 71 p.

CAPES. Comissão de Avaliação. Reformulação do sistema de avaliação da pós-graduação: o modelo a ser implantado na avaliação de 1998; documento em discussão. Disponível em: <http://www.capes.gov.br.> Acesso em: 15 maio 1999a.

CAPES. Comissão de Avaliação. Documento sobre a pós-graduação na subárea e descrição da sistemática de trabalho de avaliação: Ciências Humanas: área de avaliação: Educação. Infocapes, Brasília, v. 7, n. 3, p. 5690, jul./set. 1999b.

CAPES. Diretoria de Avaliação. Área de avaliação: indicadores. Brasília, 1998a. 22 p. Digitado.

CAPES. Diretoria de Avaliação. Avaliação da pós-graduação: síntese dos resultados. Brasília, 1995. 49 p.

CAPES. Diretoria de Avaliação. Avaliação da pós-graduação - 1998: síntese dos resultados. Brasília, 1999. 87 p.

CAPES. Diretoria de Avaliação. Avaliação dos programas de pós-graduação: base conceitual. Brasília, 1998b. 31 p. Digitado.

CAPES. Diretoria de Avaliação. Programa: síntese, indicadores e relações nominais. Brasília, 1998c. 49 p. Digitado.

CASTRO, C. de M. Educação brasileira: consertos e remendos. Rio de Janeiro: Zahar, 1985. 
CASTRO, C. de M. Na contramão da história. Veja, São Paulo, v. 34, n. 28, p. 22, jul. 2001.

CASTRO, C. de M. Onde estão os puxões de orelha e os prêmios? Veja, São Paulo, v. 31, n. 1, p. 86, jan. 1998.

CASTRO, C. de M.; SOARES, G. A. D. As avaliações da CAPES. In: SCHWARTZMAN, S.; CASTRO, C. de M. (Org.). Pesquisa universitária em questão. Campinas: Ed. da Unicamp, 1986. p. 173-189.

CERVI, R. de M. Entrevista concedida pela Coordenadora do PPGE da UFPR: 1988-1989 e 1990-1991. Curitiba, 05 abr. 2001.

CERVI, R. de M. O Programa de Pós-Graduação em Educação: notícia histórica. Educar, Curitiba, v. 7, n. 1/2, p. 169-174, jan./dez. 1988.

D'AMARAL, M. T. Nota sobre a organização de um curso de pós-graduação nos moldes de um programa de pesquisa. IBICT, Brasília, v. 10, n. 6, nov./dez. 1990.

DURHAM, E. A universidade brasileira: os impasses da transformação. Ciência e Cultura, São Paulo, v. 38, n. 12, p. 2.004-2.018, dez. 1986.

DURHAM, E.; GUSSO, D. Pós-graduação no Brasil: problemas e perspectivas. In: SEMINÁRIO INTERNACIONAL SOBRE TENDÊNCIAS DA PÓS-GRADUAÇÃO, 1991, Brasília. Anais... Brasília: MEC/Capes, 1991.

GLASER, N. Z. R. R. Educação na história da UFPR: apontamentos para uma crítica cronológica. Educar, Curitiba, v. 7, n. 1/2, p. 13-58, jan./dez. 1988.

GRACELli, A.; CASTRO, C. de M. O desenvolvimento da pós-graduação no Brasil. Ciência e Cultura, São Paulo, v. 37, n. 7, p. 188-201, jul. 1985. Suplemento.

GUIMARÃES, J. A. Opportunities and common goals for research in the Americas. In: DISCUSSÃO da pós-graduação brasileira. Brasília: Capes, 1996. v. 1, p. 9-16.

MAGGIE, Y. Graduação e pós-graduação em ciências humanas no Brasil: desafios e perspectivas. In: DISCUSSÃO da pós-graduação brasileira. Brasília: Capes, 1996. v. 1, p. 19-28. 
OLIVEIRA, F. B. de. Pós-graduação: educação e mercado de trabalho. Campinas: Papirus, 1995. 203 p.

PAVÃO, Z. M. Entrevista concedida pela Diretora do PPGE da UFPR: 1982-1991. Curitiba, 14 mar. 2001.

SAAVEDRA, S. M. G. Pesquisa, educação e desenvolvimento: uma reflexão necessária. Educação Brasileira, Brasília, v. 11, n. 23, p. 69-79, 1989.

SAVIANI, D. A pós-graduação em educação no Brasil: trajetória, situação atual e perspectivas. Revista Diálogo Educacional, Curitiba, v. 1, n. 1, p. 21-39, jan./jun. 2000.

SCHWARTZMAN, S. A ciência na universidade: a experiência histórica. Ciência e Cultura, São Paulo, v. 29, n. 11, p. 1249-1253, nov. 1977.

SCHWARTZMAN, S. A pós-graduação. Folha de S. Paulo, 14 jul. 1991. p. 6.

SPAGNOLO, F. O mais e o menos do mestrado brasileiro. Infocapes, Brasília, v. 6, n. 1, p. 45-47, jan./mar. 1998.

SPAGNOLO, F.; GÜNTHER, H. 20 anos de pós-graduação: o que fazem nossos mestres e doutores? Uma visão geral. Ciência e Cultura, São Paulo, v. 38, n. 10, p. 1643-1662, out. 1986.

UNIVERSIDADE FEDERAL DO PARANÁ. Coordenador (1992-1996: Pedra). Relatório do Coordenador do Mestrado em Educação: da reforma de 1992 a 1994. Curitiba, 1995. 87 p.

UNIVERSIDADE FEDERAL DO PARANÁ. Setor de Educação. Mestrado em Educação: área de concentração currículo. Curitiba, 1977. 14 p.

UNIVERSIDADE FEDERAL DO PARANÁ. Setor de Educação. [Proposta para doutorado]. [Curitiba, 2000]. 1 disquete.

UNIVERSIDADE FEDERAL DO PARANÁ. Setor de Educação. Programa de Pós-Graduação em Educação. Mestrado em Educação: normas para o processo de seleção de candidatos para o ano de 1998. Curitiba, 1997. 20 p.

UNIVERSIDADE FEDERAL DO PARANÁ. Setor de Educação. Programa de Pós-Graduação em Educação. Mestrado em Educação: normas para o processo de seleção de candidatos para o ano de 1999. Curitiba, 1998. 20 p. 
BUFREM, L. S. et. al. 25 anos do programa de pós-grauação...

UNIVERSIDADE FEDERAL DO PARANÁ. Setor de Educação. Programa de Pós-Graduação em Educação. Mestrado em Educação: normas para o processo de seleção de candidatos para o ano de 2000. Curitiba, 1999. 20 p.

UNIVERSIDADE FEDERAL DO PARANÁ. Setor de Educação. Regimento do curso de pós-graduação em Educação: Mestrado. Curitiba, 1977.

VIEIRA, C. A. Entrevista concedida pelo Coordenador do PPGE da UFPR: 2001. Curitiba, 13 jun. 2001. 